\title{
Hyperglycemia downregulates Connexin36 in pancreatic islets via the upregulation of ICER-1/ICER-1 $\gamma$
}

\author{
Jacques-Antoine Haefliger, Françoise Rohner-Jeanrenaud', Dorothée Caille ${ }^{2}$, \\ Anne Charollais ${ }^{2}$, Paolo Meda $^{2}$ and Florent Allagnat
}

Service of Internal Medicine, Department of Physiology, University Hospital Lausanne, Bugnon 7a, 1005 Lausanne, Switzerland

${ }^{1}$ Division of Endocrinology and Diabetology ${ }^{2}$ Department of Cell Physiology and Metabolism, School of Medicine, C.M.U. University of Geneva, Genève, Switzerland
Correspondence should be addressed to F Allagnat

Email

florent.allagnat@chuv.ch

\begin{abstract}
Channels formed by the gap junction protein Connexin36 (CX36) contribute to the proper control of insulin secretion. We previously demonstrated that chronic exposure to glucose decreases Cx36 levels in insulin-secreting cells in vitro. Here, we investigated whether hyperglycemia also regulates $\mathrm{Cx} 36$ in vivo. Using a model of continuous glucose infusion in adult rats, we showed that prolonged (24-48 h) hyperglycemia reduced the Cx36 gene Gjd2 mRNA levels in pancreatic islets. Accordingly, prolonged exposure to high glucose concentrations also reduced the expression and function of $\mathrm{Cx} 36$ in the rat insulin-producing INS-1E cell line. The glucose effect was blocked after inhibition of the CAMP/PKA pathway and was associated with an overexpression of the inducible CAMP early repressor ICER$1 /$ ICER-1 $\gamma$, which binds to a functional CAMP-response element in the promoter of the Cx36 gene Gjd2. The involvement of this repressor was further demonstrated using an antisense strategy of ICER-1 inhibition, which prevented glucose-induced downregulation of Cx36. The data indicate that chronic exposure to glucose alters the in vivo expression of $\mathrm{C} \times 36$ by the insulin-producing $\beta$-cells through ICER-1/ICER-1 $\gamma$ overexpression. This mechanism may contribute to the reduced glucose sensitivity and altered insulin secretion, which contribute to the pathophysiology of diabetes.
\end{abstract}
Key Words
- gap junctions
- connexin36
- glucose
- ICER-1

Journal of Molecular Endocrinology (2013) 51, 49-58

\section{Introduction}

Most cells communicate with each other by gap junctions, which provide a direct pathway for the intercellular diffusion of small cytosolic molecules (Bosco et al. 2011). Others and we have demonstrated that Connexin36 (Cx36) is the sole connexin expressed in the gap junctions of the insulinproducing $\beta$-cells (Theis et al. 2004, Serre-Beinier et al. 2009). The cell-to-cell communication mediated by Cx36 channels is essential for the proper regulation of storage (Serre-Beinier et al. 2009) and release of insulin (Hamelin et al. 2009, Head et al. 2012) and contributes to the resistance of $\beta$-cells to aggressive conditions (Klee et al. 2011, Meda 2012, Haefliger et al. 2013). These results suggest that alterations of the endogenous levels of Cx36, e.g. after exposure to a diabetogenic environment, could have major effects on 
$\beta$-cell function, thus contributing to the onset and progression of the disease (Hamelin etal. 2009, Bosco etal. 2011).

The prevalence of type 2 diabetes (T2D) is increasing at an alarming rate due to the combination of aging, urbanization, increasing prevalence of obesity, and physical inactivity (Wild et al. 2004). Chronic hyperglycemia and hyperlipidemia severely impact on $\beta$-cell function and survival, contributing to the progressive $\beta$-cell failure, which is central to the development of T2D and metabolic syndrome (Robertson 2009, Poitout et al. 2010). Still, the molecular and cellular mechanisms leading to the $\beta$-cell failure remain to be fully unraveled. The experimental evidence summarized above supports a likely role of Cx36. Prolonged in vitro exposure to high concentrations of glucose inhibits Cx36 expression in insulin-secreting cells (Allagnat et al. 2005), and Cx36 levels are decreased in hypercholesterolemic Apoe ${ }^{-/-}$mice (Haefliger et al. 2013) or mice consuming a high-fat diet (Allagnat et al. 2008). Here, we studied whether hyperglycemia also resulted in Cx36 downregulation in vivo, using a model of continuous glucose infusion in adult rats (Bedoya \& Jeanrenaud $1991 a, b)$. We report that long-term glucose oversupply leads to a progressive downregulation of the islet Cx36 in vivo. We have recently shown that the $\mathrm{Cx} 36$ gene $G j d 2$ is a target of the inducible cAMP early repressor ICER$1 /$ ICER-1 $\gamma$ (Allagnat et al. 2008), which is induced by glucose (Abderrahmani et al. 2006). Therefore, we further investigated whether ICER-1/ICER- $1 \gamma$ was implicated in the glucose-induced downregulation of Cx36 in the insulin-producing INS-1E cell line. We report that the expression levels of ICER-1/ICER- $1 \gamma$ are inversely related to those of Cx36 and that the repressor directly binds to the promoter of Gjd2 to mediate the downregulation of Cx36 expression during a prolonged exposure to high glucose concentrations.

\section{Materials and methods}

\section{Animal experiments}

All experiments were conducted as per the rules and under the authorization of the Veterinary Office of the State of Geneva. Three-four-month-old male Sprague-Dawley rats (300-450 g) were anesthetized by inhalation of $3 \%$ isoflurane in air and equipped with a right femoral vein catheter as described previously (Bedoya \& Jeanrenaud $1991 a, b)$. After a week of recovery, during which the implanted catheter was infused with $0.9 \% \mathrm{NaCl}$ containing $5 \mathrm{IU} / \mathrm{ml}$ heparin and $2000 \mathrm{IU} / \mathrm{ml}$ penicillin, the experimental infusion was started by a bolus injection, via the implanted catheter, of $350 \mathrm{mg} / \mathrm{kg}$ D-glucose (given as a $40 \% \mathrm{w} / \mathrm{v}$ solution in $0.9 \% \mathrm{NaCl}$ ) and continued up to the end of the experiment by connecting the catheter to an infusion pump that delivered $180 \mathrm{mg} / \mathrm{kg}$ per min clinical-grade, pyrogen-free D-glucose (given as a $20 \%$ $\mathrm{w} / \mathrm{v}$ solution) for $6,12,24$, or $48 \mathrm{~h}$. Controls received similar volumes of $0.9 \% \mathrm{NaCl}$. Four to seven rats were prepared per time point. Before starting the infusion, and periodically throughout it, blood samples were taken from the tail of each rat for the measurement of plasma glucose and insulin concentrations. Plasma concentrations of glucose were measured using the Ascencia $D E X^{2}$ blood glucose meter Bayer (Schweiz) AG, Zürich, Switzerland. Plasma insulin levels were determined using an ultrasensitive rat insulin ELISA (Mercodia, Uppsala, Sweden). At the end of each infusion, rats were anesthetized by isoflurane ventilation, and their pancreas rapidly inflated through the main pancreatic duct, with a collagenase solution (Ravier et al. 2005, Klee et al. 2011). Islets of Langerhans were isolated, purified on histopaque gradients, and individually handpicked to minimize contamination by exocrine pancreatic remnants (Ravier et al. 2005, Klee et al. 2011).

\section{Cell experiments}

The rat insulinoma cell line INS-1E (kindly provided by Dr Pierre Maechler, CMU, University of Geneva) was maintained in the complete RPMI 1640 medium, containing $11 \mathrm{mmol} / \mathrm{l}$ glucose, as described previously (Merglen et al. 2004). Cells were kept at $37^{\circ} \mathrm{C}$ in a humidified incubator under $5 \% \mathrm{CO}_{2}(\mathrm{v} / \mathrm{v})$. Cultures were exposed for various periods of time to the same culture medium, containing glucose at concentrations varying from 5 to $25 \mathrm{mmol} / \mathrm{l}$, as indicated. Some of these experiments were carried out in the presence of $5 \mu \mathrm{m}$ of the PKA inhibitor H89 (Sigma-Aldrich Chemie GmbH, Buchs, Switzerland).

\section{RNA isolation and quantitative RT-PCR (Lightcycler@)}

mRNA of the isolated islets and INS-1E cells was isolated using nucleospin RNA II columns (MACHEREY-NAGEL AG, Oensingen, Switzerland) and the Tripure Isolation Reagent (Roche Diagnostics SA, Rotkreuz, Switzerland) respectively. Transcripts $(1 \mu \mathrm{g})$ were reverse-transcribed using the ImProm-2 Reverse transcription System (Promega AG, Dübendorf, Switzerland). Quantitative PCR was performed using the SYBR Premix ExTaq (Takara Bio Europe/SAS, Saint-Germain-en-Laye, France) in a

Published by Bioscientifica Ltd. 
Lightcycler Instrument (Roche Diagnostics). cDNAs were amplified using the following primers: rat Cx36 Gjd2: 5'-ATACAGGTGTGAATGAGGGAGGATG-3' (sense) and 5'TGGAGGGTGTTACAGATGAAAGAGG-3' (antisense); rat ribosomal protein Rpl27: 5'-GATCCAAGATCAAGTCC TTTGTG-3' (sense) and 5'-CTGGGTCTCTGAACACATCC T-3' (antisense); Ins2: 5'-TGGCTTCTTCTACACACC-3' (sense) and $5^{\prime}$-TCTAGTTGCAGTAGTTCT- $3^{\prime}$ (antisense); Icer1: $5^{\prime}$-CTGGGT CTCTGAACACATCCT-3' (sense) and 5'-C ACCTTGTGGCAAAGCAGTA-3' (antisense); Rph3al: $5^{\prime}$-GGC ACACTCTCTGGAGGAAG-3' (sense) and 5'-GGGGAGGGGC AATAAAT-AAA-3' (antisense); Rab3a: 5'-GTCAGCAC TGTGGGCATAGA-3' (sense) and 5'-TGCACTGCATTGAAGGACTC-3' (antisense); and Gapdh: 5'-GACTCCACGACATAC TCAGC-3' (sense) and 5'-GTCGGTGTGAACGGATTTGG-3' (antisense). All data were normalized to the housekeeping gene Rpl27, whose expression was constant in these experiments.

\section{Western blotting}

INS-1E cells were solubilized by sonication in SDS buffer ( $62.5 \mathrm{mmol} / \mathrm{l}$ Tris-EDTA, pH 6.8; SDS 5\% v/v). Protein content was measured using a detergent-compatible BCA protein assay kit (Pierce, Thermo Fisher Scientific, Lausanne, Switzerland). Western blotting was carried out as described previously (Allagnat et al. 2005). Membranes were saturated for $1 \mathrm{~h}$ in TBS containing $5 \% \mathrm{w} / \mathrm{v}$ milk and $0.05 \% \mathrm{v} / \mathrm{v}$ Tween-20, prior to an overnight hybridization at $4{ }^{\circ} \mathrm{C}$ with either rabbit polyclonal antibodies against Cx36 (Le Gurun et al. 2003, Martin et al. 2003), diluted $1: 200$, or monoclonal anti- $\alpha$-tubulin antibodies (Fluka Chemie, Sigma-Aldrich Chemie GmbH, Buchs, Switzerland, diluted 1:2000). CREM-1/ICER-1/ICER- $1 \gamma$ western blotting was performed on nuclear extracts using the rabbit polyclonal anti-CREM-1 sc440 (Santa Cruz Biotechnology, Inc. Heidelberg, Germany, 1:2000) as described previously (Allagnat et al. 2008, Favre et al. 2011, Haefliger et al. 2013). After incubation at room temperature $(1 \mathrm{~h})$ with a convenient secondary antibody conjugated to HRP (Fluka Chemie, Sigma-Aldrich Chemie GmbH, Buchs, Switzerland, diluted 1:20 000), membranes were revealed by enhanced chemiluminescence (ECL, Amersham Biosciences, GE Healthcare Europe GmbH, Glattbrugg, Switzerland). Densitometric analyses of immunolabeled proteins (western blots films) were performed using the Image Quant Software (Molecular Dynamics, Amersham Biosciences, GE Healthcare Europe GmbH, Glattbrugg, Switzerland).

\section{Transient transfection and luciferase assays}

INS-1E cells plated in 24-well dishes were transiently transfected using Lipofectamine 2000 Reagent (Invitrogen) and a DNA:lipid ratio of $1: 1$, according to the manufacturer's instructions. All experiments involved the simultaneous transfection of a plasmid containing the mouse luciferase gene under the control of a $1 \mathrm{~kb}$ fragment of the human GJD2 promoter, the internal control plasmid pRL-SV40 (Promega), and an empty vector (pCDNA3), a pCDNA3 allowing for the constitutive expression of ICER-1 (Molina et al. 1993), or a pCDNA3 coding for a ICER-1/ICER- $\gamma \gamma$ antisense construct (Abderrahmani et al. 2006). Twenty-four hours after transfection, the cells were incubated at various glucose concentrations for another $24 \mathrm{~h}$. Cells were lysed in $100 \mu \mathrm{l}$ ice-cold Passive Lysis Buffer for 15 min, and the firefly and Renilla luciferase activities were immediately measured using $50 \mu$ lysate and the Dual-Luciferase Reporter Assay System (Promega). The Firefly activity was normalized to the Renilla activity.

\section{Chromatin immunoprecipitation assay}

INS-1E cells $\left(10^{6}\right.$ cells) were cross-linked with $1 \%$ formaldehyde at room temperature for $10 \mathrm{~min}$. The cross-linking reaction was stopped by adding glycine to a final concentration of $125 \mathrm{nmol} / \mathrm{l}$. Cells were collected and resuspended in the SDS lysis buffer $(1 \% \mathrm{v} / \mathrm{v}$ SDS, $10 \mathrm{mmol} / \mathrm{l} \mathrm{EDTA}$, and $50 \mathrm{mmol} / \mathrm{l}$ Tris/HCl, $\mathrm{pH} 8.1$ ). Cell pellets were lysed and sonicated to obtain the desired chromatin length ( $\sim 500 \mathrm{bp})$. Protein concentration of the cell supernatants was determined by the BCA protein assay (Pierce, Thermo Fisher Scientific, Lausanne, Switzerland), and the samples were diluted to $1 \mathrm{mg} / \mathrm{ml}$ in the chromatin immunoprecipitation (ChIP) dilution buffer $(1 \% \mathrm{v} / \mathrm{v}$ Triton X-100, $2 \mathrm{mmol} / \mathrm{l}$ EDTA, $150 \mathrm{mmol} / \mathrm{l} \mathrm{NaCl}$, $20 \mathrm{mmol} / \mathrm{l}$ Tris-HCl, $\mathrm{pH} 8.1$, and protease inhibitors). Samples were precleared by incubation with blocked protein A Sepharose (Amersham Biosciences) for at least $1 \mathrm{~h}$ at $4{ }^{\circ} \mathrm{C}$. The precleared chromatin lysates were immunoprecipitated overnight at $4{ }^{\circ} \mathrm{C}$ with polyclonal rabbit antibodies to CREM-1 (Santa Cruz Biotechnology), c-Myc (9E10, Santa Cruz Biotechnology), or human REST (Martin et al. 2003). The DNA-protein-antibody complexes were collected by the addition of protein $\mathrm{A}$ Sepharose for $2 \mathrm{~h}$ at $4{ }^{\circ} \mathrm{C}$. Then, the DNA-protein complexes were washed twice in a low-salt wash buffer (0.1\% v/v SDS, $1 \% \mathrm{v} / \mathrm{v}$ Triton X-100, $2 \mathrm{mmol} / 1$ EDTA, $20 \mathrm{mmol} / \mathrm{l} \mathrm{Tris}-\mathrm{HCl}$, and $150 \mathrm{mmol} / \mathrm{l} \mathrm{NaCl}$ ) and once in a

Published by Bioscientifica Ltd. 
high-salt final wash buffer $(0.1 \% \mathrm{v} / \mathrm{v}$ SDS, $1 \% \mathrm{v} / \mathrm{v}$ Triton $\mathrm{X}-100,2 \mathrm{mmol} / \mathrm{l}$ EDTA, $20 \mathrm{mmol} / \mathrm{l}$ Tris-HCl, and $500 \mathrm{mmol} / \mathrm{l} \mathrm{NaCl}$ ). The complexes were eluted from the sepharose beads by incubation at room temperature for $15 \mathrm{~min}$ in $1 \% \mathrm{v} / \mathrm{v}$ SDS and $100 \mathrm{mmol} / \mathrm{NaHCO}_{3}$. Eluates were heated for at least $4 \mathrm{~h}$ at $65^{\circ} \mathrm{C}$ to reverse the formaldehyde cross-linking and precipitated overnight at $-20^{\circ} \mathrm{C}$. The pellets were diluted in TE, RNAse A- and Proteinase K-treated, and purified using the PCR product cleanup kit (Roche Diagnostics) according to the manufacturer's instructions. DNA was submitted to standard PCR amplification or lightcycler (one cycle at $95^{\circ} \mathrm{C}$ for $3 \mathrm{~min}$, followed by 32 cycles at $94^{\circ} \mathrm{C}$ for $25 \mathrm{~s}, 58^{\circ} \mathrm{C}$ for $25 \mathrm{~s}, 72^{\circ} \mathrm{C}$ for $25 \mathrm{~s}$, and finally one cycle at $72{ }^{\circ} \mathrm{C}$ for $3 \mathrm{~min}$ ), using primers $5^{\prime}$-CACCAGCGTGTCTGTTCCT- $3^{\prime}$ (sense) and 5'-ATCTTGCGGTCTGAGGGAG-3' (antisense).

\section{Cell coupling}

Three-day-old cultures of INS-1E cells were exposed for $24 \mathrm{~h}$ to the complete RPMI 1640 medium containing either 2 or $20 \mathrm{mmol} / \mathrm{l}$ glucose. The dishes were then transferred onto the heated $\left(37^{\circ} \mathrm{C}\right)$ stage of an inverted Zeiss ICM35 microscope, and individual cells were microinjected for $5 \mathrm{~min}$, using glass pipettes containing $4 \%$ Lucifer Yellow CH (Sigma-Aldrich Chemie GmbH), in $10 \mathrm{mmol} / 1 \mathrm{HEPES}$-buffered (pH 7.2) $150 \mathrm{mmol} / 1 \mathrm{LiCl}$, and square negative pulses of $0.1 \mathrm{nA}$ amplitude, $900 \mathrm{~ms}$ duration, and $0.5 \mathrm{~Hz}$ frequency (Charpantier et al. 2007, Bavamian et al. 2012). Coupling extent was calculated after each injection by scoring the number of cells containing the injected tracer. Coupling incidence was determined by calculating the percentage of injections resulting in the cell-to-cell transfer of the tracers. Coupling index was obtained by coupling extent $\mathrm{X}$ coupling incidence.

\section{Statistical analyses}

Data are expressed as mean \pm s.E.M. Differences between means were assessed by Student's $t$-test. In experiments involving the comparison of more than two groups, ANOVA was used, followed by a $t$-test with Bonferroni correction. Real-time PCR data statistics were obtained by comparing, at each time point, the RNA levels observed in islets isolated from rats infused by $\mathrm{NaCl}$ to those observed in glucose-infused rats. Coupling data were analyzed by both ANOVA (extent) and the nonparametric $\chi^{2}$ test (incidence). All computations were carried out using either the JMP software, version 3.2.2 (SAS Institute, Cary, NC, USA), or IBM SPSS Statistics 2 (SPSS, Inc.). The $\alpha$-level of all tests was set at 0.05 . Statistical significance was defined at a value of ${ }^{*} P<0.05,{ }^{* *} P<0.01$, and ${ }^{* * *} P<0.001$.

\section{Results}

\section{Chronic hyperglycemia downregulates the in vivo expression of islet $\mathrm{Cx} 36$}

The levels of plasma glucose and insulin were constant in the control rats that were infused with $0.9 \% \mathrm{NaCl}$ for up to $48 \mathrm{~h}$ (Table 1), averaging $5.6 \pm 0.1 \mathrm{mmol} / 1$ and 0.8 $\pm 0.05 \mathrm{ng} / \mathrm{ml}$ respectively in the 46 rats that were studied. In contrast, the companion rats, which were infused in parallel with glucose, showed significantly $(P<0.001)$ higher levels of both plasma glucose and insulin at all time points (Table 1). However, while the levels of glucose increased with the duration of the glucose perfusion, those of insulin increased for the first $24 \mathrm{~h}$ of this perfusion, declining thereafter between 24 and $48 \mathrm{~h}$ (Table 1). The data validate the utility of the rat model in reproducing the major blood alterations of T2D in vivo. Quantitative

Table 1 Biological parameters evaluated in the $\mathrm{NaCl}$ - and glucose-infused rats, immediately prior to the pancreas sampling, which ended the in vivo part of the experiments. Data are mean \pm s. E.M. values of the number of rats indicated in the right column

\begin{tabular}{|c|c|c|c|c|c|}
\hline Time $(h)$ & Infusion & Glycemia $(\mathrm{mmol} / \mathrm{l})$ & Insulinemia (ng/ml) & Body weight (g) & Number of rats \\
\hline 0 & None & $5.6 \pm 0.1$ & $0.8 \pm 0.05$ & $372 \pm 6.4$ & 46 \\
\hline \multirow[t]{2}{*}{6} & $\mathrm{NaCl}$ & $5.6 \pm 0.1$ & $0.7 \pm 0.2$ & $321 \pm 16$ & 5 \\
\hline & Glucose & $14.9 \pm 1.7^{\dagger}$ & $9.4 \pm 1.2^{\dagger}$ & $344 \pm 8$ & 7 \\
\hline \multirow[t]{2}{*}{12} & $\mathrm{NaCl}$ & $6.0 \pm 0.2$ & $0.9 \pm 0.1$ & $368 \pm 18$ & 6 \\
\hline & Glucose & $12.6 \pm 0.6^{\dagger}$ & $11.3 \pm 0.9^{\dagger}$ & $393 \pm 14$ & 7 \\
\hline \multirow[t]{2}{*}{24} & $\mathrm{NaCl}$ & $5.5 \pm 0.2$ & $1.1 \pm 0.2$ & $402 \pm 13$ & 4 \\
\hline & Glucose & $18.9 \pm 2.8^{*}$ & $20.7 \pm 2.7^{\dagger}$ & $395 \pm 23$ & 6 \\
\hline \multirow[t]{2}{*}{48} & $\mathrm{NaCl}$ & $5.7 \pm 0.3$ & $1.0 \pm 0.1$ & $395 \pm 20$ & 5 \\
\hline & Glucose & $19.4 \pm 1.7^{\dagger}$ & $7.9 \pm 1.1^{\dagger}$ & $399 \pm 18$ & 6 \\
\hline
\end{tabular}

${ }^{*} P<0.01$ and ${ }^{\dagger} P<0.001$ compared with the corresponding value in the rats perfused with $0.9 \% \mathrm{NaCl}$, as evaluated by ANOVA.

http://jme.endocrinology-journals.org DOI: 10.1530/JME-13-0054
() 2013 Society for Endocrinology Printed in Great Britain
Published by Bioscientifica Ltd. 
A
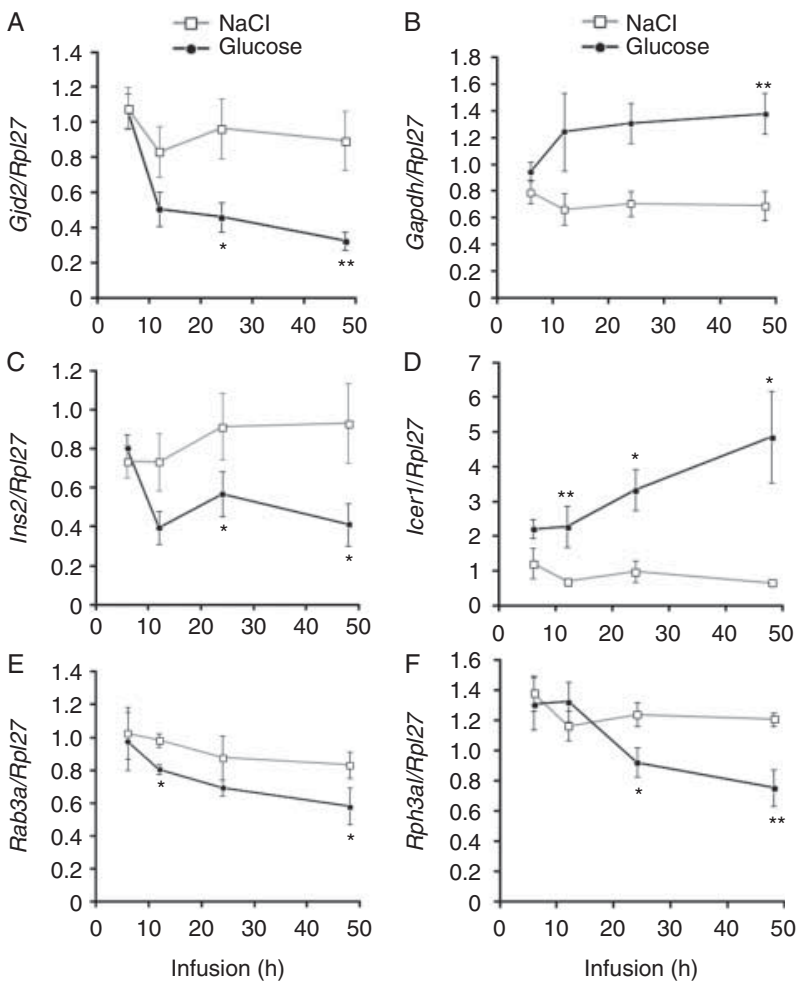

\section{Figure 1}

Chronic hyperglycemia differentially affected the transcription of different islet genes. Quantitative RT-PCR analysis showed that the expression of Gjd2, the transcript coding Cx36 (A), Gapdh (B), Ins2 (C), Icer1 (D), Rab3a (E), and Rph3al (F) mRNAs was not affected by $\mathrm{NaCl}$ perfusion. In contrast, sustained hyperglycemia progressively downregulated the expression of Gjd2 (A) and Ins2 (C) and of the two ICER-1 $\gamma$ target genes Rab3a (E) and Rph3al (F). In the very same rats, the expression of Gapdh (B) and Icer1 mRNAs (D) was increased. Data are expressed after normalization to the mRNA levels of the housekeeping ribosomal Rp/27 gene, whose expression was constant in these experiments. Normalized data are shown as mean \pm s.E.M. of at least four rats per time point. ${ }^{*} P<0.05$ and ${ }^{*} P<0.01$ vs the respective $\mathrm{NaCl}$-infused group.

RT-PCR analysis of total RNA extracted from the islets isolated immediately after the end of each perfusion revealed that the levels of several transcripts, including those of Gjd2, Ins2, Gapdh, Icer, Rab3a, and Rph3al, were not significantly modified, throughout the experiment, in the control rats perfused with $0.9 \% \mathrm{NaCl}$ (Fig. 1), which remained normoglycemic (Table 1). In contrast, significant changes in these transcripts were observed in the samples of the glucose-infused rats (Fig. 1), which became hyperglycemic (Table 1). Thus, while the transcripts of Gjd2, Ins2, Rab3a, and Rph3al decreased with the perfusion time, those of Gapdh and Icer1 increased in parallel in the very same rats (Fig. 1). Gapdh mRNA expression is known to be upregulated by glucose (Roche et al. 1997) and, thus, was used as a positive control in the glucose-infused tissue extracts. The data show that chronic hyperglycemia differentially regulates a variety of islet genes in vivo and specifically downregulates the transcriptional expression of Gjd2, which codes for Cx36. The concomitant increase in ICER-1/ICER-1 $\gamma$, a transcriptional repressor involved in the effect of palmitate on Cx36 expression (Allagnat et al. 2008 ), and the decrease in protein RAB3A and protein NOC2, two ICER-1/ICER- $1 \gamma$ targets (Abderrahmani et al. 2006), suggested that this inducible early repressor may mediate the effect of high glucose concentrations on Cx36 expression.

\section{Chronic exposure to high glucose concentrations downregulates the in vitro expression of INS-1E Cx36}

To experimentally investigate this plausible molecular mechanism, we used the rat insulin-producing line INS-1E. In the presence of high glucose concentrations, these cells also reduced their native CX36 protein expression (Fig. 2A and $\mathrm{B}$ ). This change was associated with a significant decrease in both the extent and the incidence of cell-to-cell coupling, as evaluated by the intercellular exchange of the gap junction tracer Lucifer Yellow (Table 2). Similar to islets, INS-1E cells exposed for a day to $20 \mathrm{mmol} / \mathrm{l}$ glucose decreased the expression of CX36, in a way which was inversely related to the parallel increase in the expression of nuclear ICER-1/ICER- $1 \gamma$, which was both time- and dose-dependent (Fig. 2A and B). In contrast, glucose had no effect on the expression of the CREM-1 protein. The glucose-mediated CX36 downregulation and overexpression of ICER-1/ICER- $1 \gamma$ were both prevented in the presence of $5 \mu \mathrm{mol} / 1$ of the cAMP-dependent protein kinase inhibitor H89 (Fig. 2C). With regard to the regulation of CX36 and ICER-1/ICER$1 \gamma$ expression, the data show that INS-1E cells mimicked in vitro the in vivo behavior of rat islets exposed to hyperglycemia.

\section{ICER-1/ICER-1 $\gamma$ regulates the expression of Cx36 in INS-1E cells}

The promoters of the human and rodent Gjd2 genes feature a highly conserved cAMP-response element (CRE) between bases -566 and -556 , upstream of the transcription start site (Allagnat et al. 2005). To test whether this element mediates the effect of high glucose concentrations on Cx36 expression, we generated a plasmid expressing the reporter gene luciferase under the control of a $1 \mathrm{~kb}$ fragment of the human GJD2 promoter, which contained the CRE (pGJD2). One day after transfection

Published by Bioscientifica Ltd. 
A

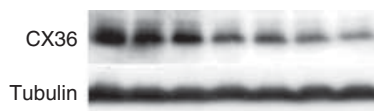

$\begin{array}{llllllll}\text { Hours } & 0 & 1 & 2 & 4 & 6 & 8 & 24\end{array}$

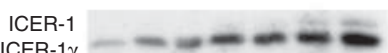

ICER-1 $1 \gamma$

CREM-1 $--m-m-m$
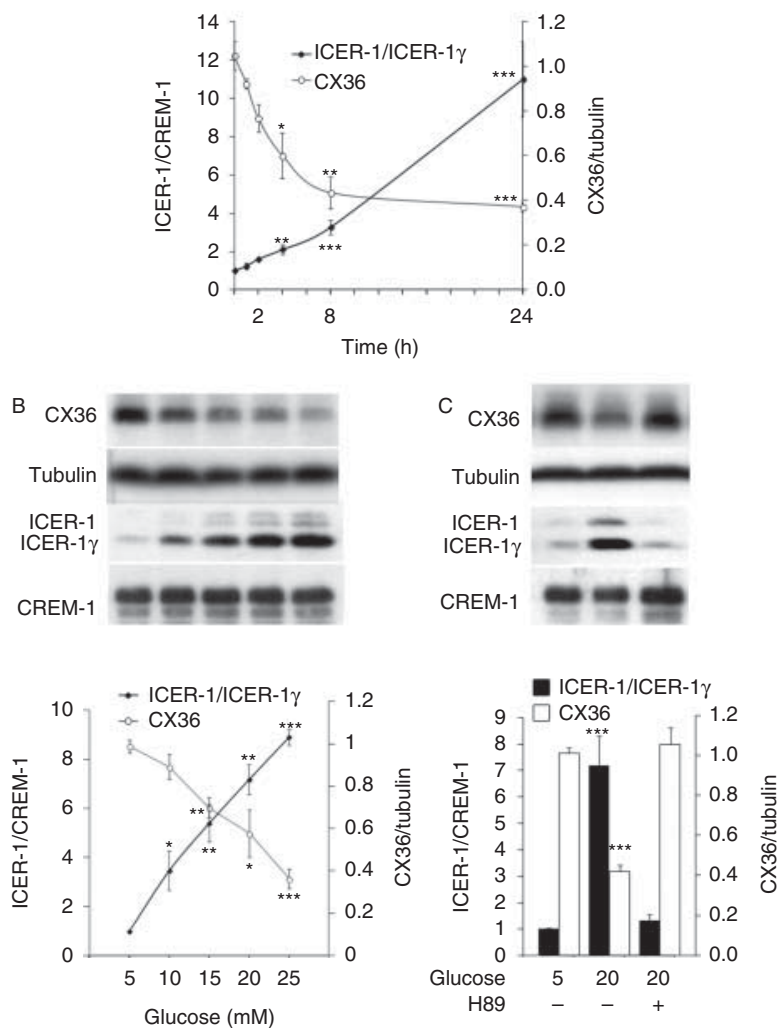

Figure 2

High glucose levels time- and dose-dependently downregulate CX36 and induce ICER-1/ICER-1 $\gamma$ expression in INS-1E cells. (A) Time-course analysis of total CX36 over tubulin and nuclear ICER-1/ICER-1 $\gamma$ over CREM-1 protein levels in INS-1E cells exposed to $20 \mathrm{mmol} / \mathrm{l}$ glucose revealed a progressive, significant increase in the ICER-1/ICER- $1 \gamma$ proteins and a parallel decrease in the $\mathrm{C} \times 36$ protein. (B) The amplitude of these two changes was almost linearly dependent on the concentration of glucose tested during the 24-h duration of these experiments. (C) Exposure to $5 \mu \mathrm{mol} / \mathrm{l}$ of PKA inhibitor H89 prevented the differential, glucose-dependent regulation of ICER-1/ ICER-1 $\gamma$ and CX36. The top part of each panel shows a representative immunoblot for CX36, ICER-1, ICER-1 $\gamma$, and the internal standards tubulin and CREM-1. The bottom part of each panel shows the densitometric analysis of three independent experiments. Data are mean \pm S.E.M. values, expressed relatively to the corresponding internal standards (tubulin for CX36 and CREM- 1 for ICER-1/ICER- $1 \gamma$ ). ${ }^{*} P<0.05, * * P<0.01$, and $* * * P<0.001$ vs the level evaluated at time $0(\mathrm{~A})$ or after a $24-\mathrm{h}$ exposure to $5 \mathrm{mmol} / \mathrm{l}$ glucose (B and C).

with pGJD2, INS-E cells were incubated for an additional $24 \mathrm{~h}$ in the presence of either 5 or $20 \mathrm{mmol} / \mathrm{l}$ glucose and then processed to evaluate the activity of the GJD2 promoter. Normalized luciferase measurements showed that the GJD2 promoter activity was $30 \%$ less $(P<0.01)$ in the cells exposed to $20 \mathrm{mmol} / \mathrm{l}$ glucose compared with those exposed to $5 \mathrm{mmol} / \mathrm{l}$ glucose (Fig. 3A). However, the effect of glucose was lost in cells transfected with a plasmid that contained the $1 \mathrm{~kb} G j d 2$ promoter in which the CRE had been point-mutated (pGJD2 mut) (Fig. 3A). Then, INS-1E cells were co-transfected with a control empty vector (pCDNA3), a plasmid coding for ICER-1 (pICER-1), or an antisense construct (pAS-ICER), which reduces the endogenous expression of ICER-1/ICER- $1 \gamma$ (Abderrahmani et al. 2006, Haefliger et al. 2013). We observed that ICER-1 overexpression (Fig. 3B) reduced by $40 \%$ the activity of the native Gjd2 promoter fragment in the cells exposed to $5 \mathrm{mmol} / \mathrm{l}$ glucose, but not in the cells exposed to $20 \mathrm{mmol} / \mathrm{l}$ glucose, and that this inhibitory effect was not observed in the cells transfected with pGJD2 mut (Fig. 3A). Conversely, co-transfection with pAS-ICER resulted in a slightly increased luciferase activity of pGJD2 in the cells exposed to $5 \mathrm{mmol} / \mathrm{l}$ glucose and restored the GJD2 activity in the cells cultured in the presence of $20 \mathrm{mmol} / \mathrm{l}$ glucose (Fig. 3A). Altogether the data show that ICER-1/ICER-1 $\gamma$ mediated the glucose effect on the GJD2 promoter activity through the CRE.

Western blot analysis of INS-1E cells transiently transfected with the plasmid encoding ICER-1/ICER- $1 \gamma$ further showed that ICER-1 overexpression (Fig. 3B) mimicked the downregulatory effect of $20 \mathrm{mmol} / \mathrm{l}$ glucose on CX36 protein levels (Fig. 3C), whereas the transfection of the antisense ICER construct, which prevented the overexpression of ICER-1/ICER- $1 \gamma$ (Fig. 3B), abolished the glucose-induced CX36 downregulation (Fig. 3C).

To assess whether this regulation involved the direct binding of ICER-1/ICER- $1 \gamma$ to the CRE of the Gjd2 promoter, we immunoprecipitated the chromatin of INS-1E cells cultured in the presence of either 5 or $20 \mathrm{mM}$

Table 2 Dye coupling of INS-1E cells after a 24-h exposure to low and high glucose concentrations

\begin{tabular}{|c|c|c|c|c|}
\hline $\begin{array}{l}\text { Glucose } \\
(\mathrm{mmol} / \mathrm{l})\end{array}$ & $\begin{array}{l}\text { Extent of } \\
\text { coupling }^{a}\end{array}$ & $\begin{array}{l}\text { Incidence of } \\
\text { coupling }^{\text {b }}\end{array}$ & $\begin{array}{l}\text { Coupling } \\
\text { index } \\
\text { (a.u.) }\end{array}$ & $\begin{array}{c}\text { Number of } \\
\text { microin- } \\
\text { jections }\end{array}$ \\
\hline 2 & $2.7 \pm 0.3$ & $20(71.4)$ & 192.8 & 28 \\
\hline 20 & $1.4 \pm 0.1 *$ & $13(40.6)^{\dagger}$ & 56.9 & 32 \\
\hline
\end{tabular}

${ }^{\text {a }}$ Data are mean \pm S.E.M. values of the number of cells featuring labeling by Lucifer Yellow, indicated in the right column. ${ }^{*} P<0.001$ compared with the value in the cells exposed to low glucose concentrations, as evaluated by ANOVA.

${ }^{\mathrm{b}}$ Number and proportion of injections that did result in the intercellular transfer of dye. ${ }^{\dagger} P<0.01$, as evaluated by the nonparametric $\chi^{2}$ test.

'Given by the average extent of coupling $X$ the percentage incidence of coupling. http://jme.endocrinology-journals.org DOI: 10.1530/JME-13-0054
() 2013 Society for Endocrinology Printed in Great Britain 


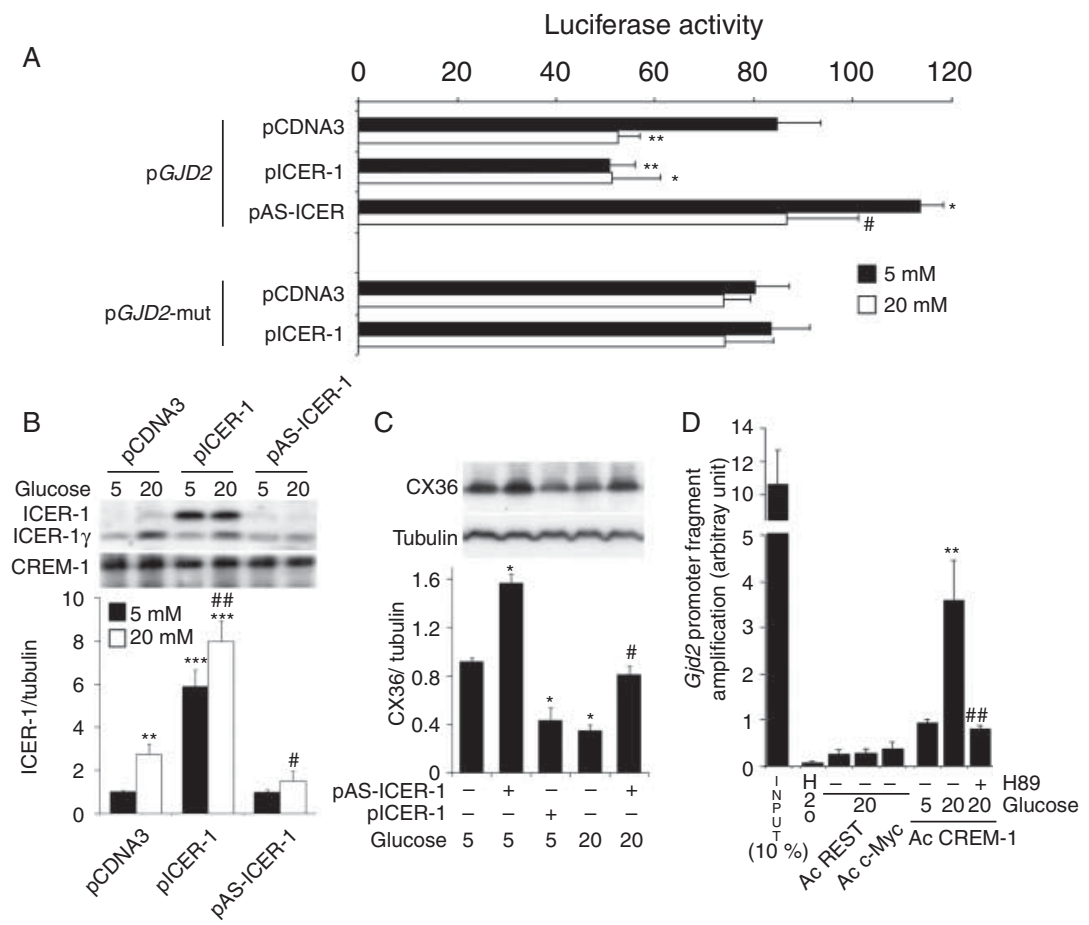

Figure 3

ICER-1/ICER- $1 \gamma$ mediates the effect of glucose on Cx36 expression, by binding to a CAMP response CRE of the $G j d 2$ promoter. (A) INS-1E cells were co-transfected with a reporter plasmid under the control of a $1 \mathrm{~kb}$ fragment of the human GJD2 promoter ( $p G J D 2$ ) or the same fragment with a mutated CRE ( $p G J D 2$ mut), together with the control empty vector pCDNA3 or a plasmid allowing either the overexpression of ICER-1 (pICER-1) or the reduction of the endogenous expression of ICER-1/ICER-1 $\gamma$ by an antisense effect (pAS-ICER-1). One day after transfection, the cells were incubated for $24 \mathrm{~h}$ in presence of either $5 \mathrm{mmol} / \mathrm{l}$ (black bars) or $20 \mathrm{mmol} / \mathrm{l}$ glucose (white bars) and assessed for luciferase activity. Results are Firefly luciferase activities normalized to Renilla luciferase activities and are shown as means \pm S.E.M. of five independent experiments. $* P<0.05$; $* * P<0.01$ vs the $p C D N A 3$-transfected cells, $5 \mathrm{mmol} / \mathrm{l}$ value. ${ }^{\#} P<0.05$ vs the pCDNA3-transfected cells, $20 \mathrm{mmol} / \mathrm{l}$ glucose. (B and C) INS-1E cells were transfected with an empty vector ( $p C D N A 3$ ) or plasmids allowing either the overexpression of ICER-1 (pICER-1) or the reduction of the endogenous ICER-1/ICER-1 $\gamma$ levels (pAS-ICER-1). Forty-eight hours after transfection, the cells were cultured for an additional $24 \mathrm{~h}$ in the presence of either 5 or $20 \mathrm{mmol} / \mathrm{l}$ glucose. (B) Western blot analysis of ICER-1/ICER-1 $\gamma$ and CREM-1 levels in nuclear extracts revealed the efficiency of the plasmid transfection. (C) Western blot analysis of CX36 and tubulin showed that ICER-1/ICER-1 $\gamma$

glucose, using antibodies to CREM-1, which recognize ICER-1 $\gamma$. Antibodies against c-Myc, which have no putative binding site in the Gjd2 promoter, and against REST, a repressor that is not expressed in $\beta$-cells (Martin et al. 2003), served as negative controls. The expected $385 \mathrm{bp}$ amplicon, corresponding to bases -796 to -411 of the Gjd2 promoter, was detected in the anti-CREM-1 immunoprecipitates, but not in the anti-Myc and the anti-REST ones (Fig. 3D). Quantitative PCR further revealed that the binding overexpression decreased CX36 expression, whereas the reduction of the repressor increased it and prevented the glucose-induced downregulation of the connexin. The top parts of panels (B) and (C) show representative Western blots; the lower parts show the densitometric evaluation of four independent experiments. Results were normalized to the internal controls (CREM-1 for ICER-1/ICER- $1 \gamma$ and tubulin for CX36) and are shown as means \pm S.E.M. of four independent experiments. ${ }^{*} P<0.05 ; * * P<0.01$, $* * * P<0.001$ vs $5 \mathrm{mmol} / \mathrm{l}$ glucose value. ${ }^{\#} P<0.05, * * P<0.01$ vs the pCDNA3transfected cells, $20 \mathrm{mmol} / \mathrm{l}$ value. (D) Chromatin was extracted from INS-1E cells cultured for $24 \mathrm{~h}$ in the presence of either 5 or $20 \mathrm{mmol} / \mathrm{l}$ glucose, with or without the PKA inhibitor H89 $(5 \mu \mathrm{mol} / \mathrm{l})$. Fixed chromatin was immunoprecipitated using antibodies to CREM-1, REST, or c-Myc, and the fragment of the Gjd2 promoter containing CRE was amplified by PCR. Quantitative RT-PCR of the immunoprecipitated promoter fragment demonstrated the binding of CREM-1, which was significantly greater in the cells exposed to $20 \mathrm{mmol} / \mathrm{l}$ glucose (D). This increase was abolished in the cells exposed to H89. No significant immunoprecipitation was observed in the cells exposed to $20 \mathrm{mmol} / \mathrm{l}$ glucose, when the chromatin was reacted with antibodies to either REST or C-Myc. Results are means \pm s.E.M. of four independent experiments. ${ }^{* *} P<0.01$ vs CREM-1, $5 \mathrm{mmol} / \mathrm{l}$ glucose value. $\# \# P<0.05$ vs CREM-1, $20 \mathrm{mmol} / /$ value.

of CREM-1 to the Gjd2 promoter was significantly increased in the cells exposed to $20 \mathrm{mM}$ glucose (Fig. 3D) and that this effect was blocked by treating the cells with H89 (Fig. 3D), which prevented the glucose-mediated overexpression of ICER-1/ICER-1 $\gamma$ (Fig. 2C). The data indicate that the direct binding of ICER-1 to the CRE of the Gjd2 promoter was necessary and sufficient to account for the downregulation of Cx36 expression observed after chronic exposure to high glucose levels.

Published by Bioscientifica Ltd. 


\section{Discussion}

Chronic exposure to increased levels of environmental glucose is deemed as one of the most deleterious changes of the milieu interieur, which, by impacting on several tissues key to metabolic regulation, plays a major role in the development and maintenance of diabetes (Stolar 2010, Inzucchi et al. 2012). Specifically, high levels of glucose are thought to have a toxic impact on the function of the insulin-producing $\beta$-cells of pancreas, which play a prominent role in most forms of the disease (Robertson 2009, Ferrannini 2010, Poitout et al. 2010). Still, the molecular mechanisms linking hyperglycemia to $\beta$-cell dysfunction are still poorly understood and the subject of much debate (Robertson 2009, Ferrannini 2010, Poitout et al. 2010). We previously documented the in vivo role of the gap junction protein Cx36 in the biosynthetic and secretory functions of $\beta$-cells (Serre-Beinier et al. 2009), as well as in the resistance of these cells to conditions eliciting hyperglycemia (Klee et al. 2011). We also reported that the expression of this protein is downregulated under several in vitro and in vivo conditions mimicking in part a diabetic environment (Allagnat et al. 2005, Haefliger et al. 2013). At this point, however, it has not been established whether a sustained elevation of the circulating levels of glucose is alone sufficient to cause such a downregulation in vivo and, if so, by which mechanism.

To address these issues, we investigated a glucoseinfused rat model. Of note, our model was designed so that the rats remained hyperglycemic throughout the experiment, in contrast with previous studies in which glycemia returned to control values $24 \mathrm{~h}$ after the beginning of infusion. In the latter, the moderate glycemia excursion allowed for $\beta$-cell adaptation via an increase in the $\beta$-cell mass, whereas in our model, the higher glycemic excursion did not allow for such compensation, resulting in $\beta$-cell failure. However, a few days of experimentally induced hyperglycemia is but an approximate model of the long-term in vivo conditions that presumably mediate the toxic effects of glucose on $\beta$-cell functions. Our purpose here was not to investigate the complex situation occurring in T2D, but rather to assess whether a sustained elevation of glucose would modulate $\mathrm{Cx} 36$ expression. In this perspective, the glucose infusion model appeared adequate to test this possibility in vivo. First, we observed that hyperglycemia rapidly stimulated the expression of the known glucose-responsive gene Gapdh (Roche et al. 1997), which validates the glucose infusion model. We further observed that chronic hyperglycemia inhibits within hours the expression of Gjd2 mRNA, in parallel with an induction of Icer1. This repressor is known to inhibit the expression of Rab3a, Rph3al, and Ins2 (Abderrahmani et al. 2006). Accordingly, the transcription of these three genes was found to be decreased in the hyperglycemic animals, validating the glucose-infused rat model and stressing the central, in vivo repressor role of ICER-1/ICER- $1 \gamma$. The data extend the in vitro observations that ICER-1/ICER- $1 \gamma$ is overexpressed in response to prolonged exposure to high glucose concentrations (Zhou et al. 2003, Abderrahmani et al. 2006) and are consistent with the report of increased levels of the repressor in the islets of diabetic GK rats (Inada et al. 1998), as well as in those of hypercholesterolemic Apoe ${ }^{-1-}$ mice (Haefliger et al. 2013) and of mice fed a high-fat diet (Allagnat et al. 2008).

To evaluate whether these coincidental changes are actually interrelated, we used the INS-1E rat insulinproducing cells in which glucose time- and dosedependently decreases Cx36 expression (Allagnat et al. 2005), like it does in the primary islets. Under these conditions, we found that glucose also time- and dosedependently stimulated ICER-1/ICER- $1 \gamma$ expression, again like in the primary islets. Antisense blockade of this overexpression prevented the glucose-dependent downregulation of CX36, indicating that ICER-1/ICER- $1 \gamma$ likely mediates the inhibitory effect of hyperglycemia on the expression of CX36. Further ChIP experiments revealed that ICER-1/ICER- $1 \gamma$ directly binds to a CRE in the promoter of the Cx36 gene Gjd2, leading to a direct downregulation of $\mathrm{C} \times 36$ transcription, which ultimately decreases the levels of the cognate protein. We further showed that under these conditions, the CX36 protein downregulation results in a decrease in the extent and incidence of coupling between INS-1E cells.

In this study, we showed that hyperglycemia specifically induces an overexpression of ICER-1/ICER- $1 \gamma$ and a concomitant downregulation of $\mathrm{Cx} 36$ in $\beta$-cells. Previous studies have documented the deleterious impact of prolonged ICER-1/ICER- $1 \gamma$ overexpression on $\beta$-cell function and survival (Inada et al. 2004, 2005, Abderrahmani et al. 2006, Allagnat et al. 2008, Favre et al. 2011). However, little is known about the ICER-1 target genes responsible for the pro-apoptotic impact of this repressor. Together with our previous research (Allagnat et al. 2008, Favre et al. 2011, Haefliger et al. 2013), the present study has identified Cx36 has a relevant ICER-1/ICER-1 $\gamma$ target. Given the requirement of a proper $\mathrm{Cx} 36$ signaling in insulin secretion and $\beta$-cell survival (Meda 2012), our data strongly suggest that $\mathrm{Cx} 36$ contributes to the deleterious sequence of events triggered by ICER-1/ICER- $1 \gamma$, which

Published by Bioscientifica Ltd. 
presumably leads to glucose desensitization and $\beta$-cell failure in the pre-diabetic stage.

\section{Declaration of interest}

The authors declare that there is no conflict of interest that could be perceived as prejudicing the impartiality of the research reported.

\section{Funding}

This work was supported by grants from the SNF (31003A-138528; 310030_141162; CR32I3_129987), the JDRF (40-2011-11; 5-2012-281), the EU (BETAIMAGE 222980; IMIDIA, C2008-T7; BETATRAIN 289932), the NIH HL64232, the Octav and the Marcella Botnar Foundation, the Novartis Foundation, and the Emma Muschamp Foundation.

\section{Author contribution statement}

F A, P M, J-A H , and F R-J designed the project. F A, F R-J, A C, D C, P M, and $J-A H$ performed the experiments. $F A, P M$, and J-A $H$ wrote the manuscript.

\section{References}

Abderrahmani A, Cheviet S, Ferdaoussi M, Coppola T, Waeber G \& Regazzi R 2006 ICER induced by hyperglycemia represses the expression of genes essential for insulin exocytosis. EMBO Journal $\mathbf{2 5}$ 977-986. (doi:10.1038/sj.emboj.7601008)

Allagnat F, Martin D, Condorelli DF, Waeber G \& Haefliger JA 2005 Glucose represses Connexin36 in insulin-secreting cells. Journal of Cell Science 118 5335-5344. (doi:10.1242/jcs.02600)

Allagnat F, Alonso F, Martin D, Abderrahmani A, Waeber G \& Haefliger JA 2008 ICER- $1 \gamma$ overexpression drives palmitate-mediated Connexin 36 down-regulation in insulin-secreting cells. Journal of Biological Chemistry 283 5226-5234. (doi:10.1074/jbc.M708181200)

Bavamian S, Pontes H, Cancela J, Charollais A, Startchik S, Van de Ville D \& Meda P 2012 The intercellular synchronization of $\mathrm{Ca}^{2+}$ oscillations evaluates Cx36-dependent coupling. PLOS ONE 7 e41535. (doi:10.1371/ journal.pone.0041535)

Bedoya FJ \& Jeanrenaud B 1991 $a$ Evolution of insulin secretory response to glucose by perifused islets from lean (FA/FA) rats chronically infused with glucose. Diabetes 40 7-14. (doi:10.2337/diabetes.40.1.7)

Bedoya FJ \& Jeanrenaud B $1991 b$ Insulin secretory response to secretagogues by perifused islets from chronically glucose-infused rats. Diabetes 40 15-19. (doi:10.2337/diabetes.40.1.15)

Bosco D, Haefliger JA \& Meda P 2011 Connexins: key mediators of endocrine function. Physiological Reviews 91 1393-1445. (doi:10.1152/ physrev.00027.2010)

Charpantier E, Cancela J \& Meda P $2007 \beta$-Cells preferentially exchange cationic molecules via connexin 36 gap junction channels. Diabetologia 50 2332-2341. (doi:10.1007/s00125-007-0807-9)

Favre D, Niederhauser G, Fahmi D, Plaisance V, Brajkovic S, Beeler N, Allagnat F, Haefliger JA, Regazzi R, Waeber G et al. 2011 Role for inducible cAMP early repressor in promoting pancreatic $\beta$ cell dysfunction evoked by oxidative stress in human and rat islets. Diabetologia 54 2337-2346. (doi:10.1007/s00125-011-2165-x)

Ferrannini E 2010 The stunned $\beta$ cell: a brief history. Cell Metabolism 11 349-352. (doi:10.1016/j.cmet.2010.04.009)

Haefliger JA, Martin D, Favre D, Petremand Y, Mazzolai L, Abderrahmani A, Meda P, Waeber G \& Allagnat F 2013 Reduction of Connexin 36 content by ICER-1 contributes to insulin-secreting cells apoptosis induced by oxidized LDL particles. PLoS ONE 8 e55198. (doi:10.1371/journal.pone. 0055198)

Hamelin R, Allagnat F, Haefliger JA \& Meda P 2009 Connexins, diabetes and the metabolic syndrome. Current Protein \& Peptide Science 10 18-29. (doi:10.2174/138920309787315167)

Head WS, Orseth ML, Nunemaker CS, Satin LS, Piston DW \& Benninger RK 2012 Connexin-36 gap junctions regulate in vivo first- and second-phase insulin secretion dynamics and glucose tolerance in the conscious mouse. Diabetes 61 1700-1707. (doi:10.2337/db11-1312)

Inada A, Yamada Y, Someya Y, Kubota A, Yasuda K, Ihara Y, Kagimoto S, Kuroe A, Tsuda K \& Seino Y 1998 Transcriptional repressors are increased in pancreatic islets of type 2 diabetic rats. Biochemical and Biophysical Research Communications 253 712-718. (doi:10.1006/bbrc. 1998.9833)

Inada A, Hamamoto Y, Tsuura Y, Miyazaki J, Toyokuni S, Ihara Y, Nagai K, Yamada Y, Bonner-Weir S \& Seino Y 2004 Overexpression of inducible cyclic AMP early repressor inhibits transactivation of genes and cell proliferation in pancreatic $\beta$ cells. Molecular and Cellular Biology 24 2831-2841. (doi:10.1128/МСB.24.7.2831-2841. 2004)

Inada A, Weir GC \& Bonner-Weir S 2005 Induced ICER Igamma downregulates cyclin A expression and cell proliferation in insulinproducing $\beta$ cells. Biochemical and Biophysical Research Communications 329 925-929. (doi:10.1016/j.bbrc.2005.02.046)

Inzucchi SE, Bergenstal RM, Buse JB, Diamant M, Ferrannini E, Nauck M, Peters AL, Tsapas A, Wender R \& Matthews DR 2012 Management of hyperglycaemia in type 2 diabetes: a patient-centered approach. Position statement of the American Diabetes Association (ADA) and the European Association for the Study of Diabetes (EASD). Diabetologia 55 1577-1596. (doi:10.1007/s00125-012-2534-0)

Klee P, Allagnat F, Pontes H, Cederroth M, Charollais A, Caille D, Britan A, Haefliger JA \& Meda P 2011 Connexins protect mouse pancreatic $\beta$ cells against apoptosis. Journal of Clinical Investigation 121 4870-4879. (doi:10.1172/JCI40509)

Le Gurun S, Martin D, Formenton A, Maechler P, Caille D, Waeber G, Meda P \& Haefliger JA 2003 Connexin-36 contributes to control function of insulin-producing cells. Journal of Biological Chemistry 278 37690-37697. (doi:10.1074/jbc.M212382200)

Martin D, Tawadros T, Meylan L, Abderrahmani A, Condorelli DF, Waeber G \& Haefliger JA 2003 Critical role of the transcriptional repressor neuron-restrictive silencer factor in the specific control of Connexin36 in insulin-producing cell lines. Journal of Biological Chemistry 278 53082-53089. (doi:10.1074/jbc.M306861200)

Meda P 2012 The in vivo $\beta$-to- $\beta$-cell chat room: connexin connections matter. Diabetes 61 1656-1658. (doi:10.2337/db12-0336)

Merglen A, Theander S, Rubi B, Chaffard G, Wollheim CB \& Maechler P 2004 Glucose sensitivity and metabolism-secretion coupling studied during two-year continuous culture in INS-1E insulinoma cells. Endocrinology 145 667-678. (doi:10.1210/en.2003-1099)

Molina CA, Foulkes NS, Lalli E \& Sassone-Corsi P 1993 Inducibility and negative autoregulation of CREM: an alternative promoter directs the expression of ICER, an early response repressor. Cell 75 875-886. (doi:10.1016/0092-8674(93)90532-U)

Poitout V, Amyot J, Semache M, Zarrouki B, Hagman D \& Fontes G 2010 Glucolipotoxicity of the pancreatic $\beta$ cell. Biochimica et Biophysica Acta 1801 289-298. (doi:10.1016/j.bbalip.2009.08.006)

Ravier MA, Guldenagel M, Charollais A, Gjinovci A, Caille D, Sohl G, Wollheim CB, Willecke K, Henquin JC \& Meda P 2005 Loss of Connexin 36 channels alters $\beta$-cell coupling, islet synchronization of glucose-induced $\mathrm{Ca}^{2+}$ and insulin oscillations, and basal insulin release. Diabetes 54 1798-1807. (doi:10.2337/ diabetes.54.6.1798)

Robertson RP 2009 -Cell deterioration during diabetes: what's in the gun? Trends in Endocrinology and Metabolism 20 388-393. (doi:10.1016/j.tem. 2009.05.004) 
Roche E, Assimacopoulos-Jeannet F, Witters LA, Perruchoud B, Yaney G, Corkey B, Asfari M \& Prentki M 1997 Induction by glucose of genes coding for glycolytic enzymes in a pancreatic $\beta$-cell line (INS-1). Journal of Biological Chemistry 272 3091-3098. (doi:10.1074/jbc.272.5. 3091)

Serre-Beinier V, Bosco D, Zulianello L, Charollais A, Caille D, Charpantier E, Gauthier BR, Diaferia GR, Giepmans BN, Lupi R et al. 2009 Cx36 makes channels coupling human pancreatic $\beta$-cells, and correlates with insulin expression. Human Molecular Genetics 18 428-439. (doi:10.1093/hmg/ddn370)

Stolar M 2010 Glycemic control and complications in type 2 diabetes mellitus. American Journal of Medicine 123 S3-S11. (doi:10.1016/j. amjmed.2009.12.004)
Theis M, Mas C, Doring B, Degen J, Brink C, Caille D, Charollais A, Kruger O, Plum A, Nepote V et al. 2004 Replacement by a lacZ reporter gene assigns mouse Connexin 36, 45 and 43 to distinct cell types in pancreatic islets. Experimental Cell Research 294 18-29. (doi:10.1016/j.yexcr.2003.09.031) Wild S, Roglic G, Green A, Sicree R \& King H 2004 Global prevalence of diabetes: estimates for the year 2000 and projections for 2030. Diabetes Care 27 1047-1053. (doi:10.2337/diacare.27.5.1047)

Zhou YP, Marlen K, Palma JF, Schweitzer A, Reilly L, Gregoire FM, Xu GG, Blume JE \& Johnson JD 2003 Overexpression of repressive cAMP response element modulators in high glucose and fatty acid-treated rat islets. A common mechanism for glucose toxicity and lipotoxicity? Journal of Biological Chemistry 278 51316-51323. (doi:10.1074/jbc. M307972200)

Received in final form 18 April 2013

Accepted 22 April 2013

Accepted Preprint published online 23 April 2013
Published by Bioscientifica Ltd. 